\title{
Eosinophilic granuloma of the mandible: a diagnostic dilemma
}

\author{
Rana K Sherwani, Kafil Akhtar, Shagufta Qadri, Prasenjit Sen Ray
}

Department of Pathology, Jawaharlal Nehru Medical College, Aligarh Muslim University, Aligarh, UttarPradesh, India

\section{Correspondence to Dr P S Ray, psenray@gmail.com}

Accepted 13 March 2014
To cite: Sherwani RK, Akhtar K, Qadri S, et al. BMJ Case Rep Published online: [please include Day Month Year] doi:10.1136/ bcr-2013-200274

\section{SUMMARY}

Eosinophilic granuloma (EG) is a rare histiocytic disorder resulting from clonal proliferation of Langerhans cells. It accounts for less than $1 \%$ of all osseous neoplasms and has a predilection for involving the axial skeleton. Although suspicion of the disease may arise from clinical features and radiographic demonstration of destructive bone lesions, it is still difficult to make a correct diagnosis without proper pathological evaluation. This is more evident when common differentials mimicking $E G$, both clinically and radiologically, need to be ruled out. This report describes a case of unifocal EG of the mandible occurring in a 4-year-old boy whose initial presentation led to confusion between osteomyelitis, primary bone tumour and lymphoma. A final diagnosis of $E G$ was established after histopathological examination of the biopsy specimen.

\section{BACKGROUND}

Langerhans cell histiocytosis (LCH) refers to a relatively rare condition resulting from neoplastic proliferation of Langerhans cells. It is a disease of unknown aetiology and diverse manifestations. Eosinophilic granuloma (EG) - a term used synonymously with $\mathrm{LCH}$ by the World Health Organisation-is a localised form of the disease. ${ }^{1}$ It is in fact the mildest form of the histiocytosis-X group of diseases, which also encompass Hand-SchullerChristian disease and Letterer-Siwe disease. The above grouping was based on the similarities of the histopathological appearance of the histiocytic and eosinophilic proliferation. ${ }^{2}$

EG accounts for less than $1 \%$ of all osseous neoplasms and occurs more commonly as solitary rather than multiple lesions. The disease has a predilection for involving the axial skeleton, and the incidence is higher among men. More than half of the patients are less than 10 years of age at the time of presentation, although people of any age can suffer from this disorder. ${ }^{1}$

In this report, we present a rare case of unifocal EG of the mandible occurring in a 4-year-old boy who was admitted with complaints of a gradually increasing swelling on the right side of his face over 1.5 years, accompanied by non-healing ulcerative lesions in the lower molar gingiva. Radiological investigations showed the presence of a lytic lesion in the mandible with floating teeth. Based on these findings, the differentials that were considered were osteomyelitis, primary bone tumour and lymphoma. However, biopsy from the lesion showed the characteristic features of EG. We highlight this unusual case and emphasise the importance of histopathological examination in the diagnosis of this rare condition.

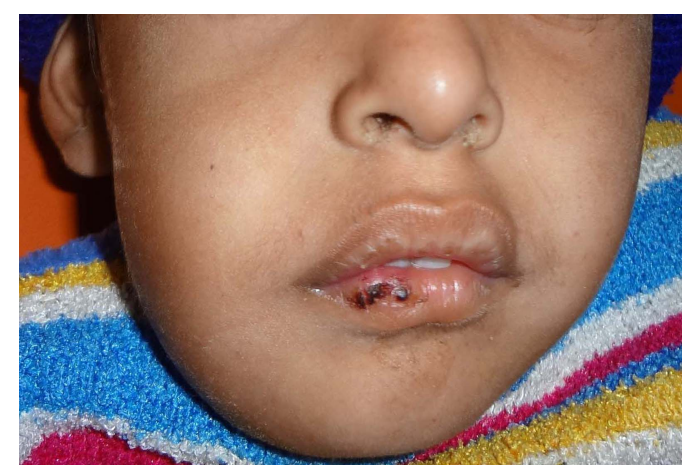

Figure 1 Solitary globular swelling on the face over the right lower jaw region, extending towards the angle of the mandible.

\section{CASE PRESENTATION}

A 4-year-old male patient was referred to the outpatient department of our hospital with complaints of pain and progressively increasing swelling on the right side of the lower jaw, over the past 1.5 years. There was difficulty in mastication and dysphagia. A low grade fever was associated from the time of onset of the swelling; however, weight loss and a history of trauma were absent. During this entire period, the patient had several trials of antimicrobials but without any effect.

Clinical examination revealed a single large globular swelling measuring approximately $5 \times 4 \mathrm{~cm}$ over the right lower jaw region with extension towards the angle of the mandible (figure 1). On palpation, the swelling had diffuse margins, was tender, firm to hard, immobile and attached to the underlying structures. Intraorally, an ulceroproliferative growth was detected around the lower gingiva on the same side (figure 2). Multiple loose teeth were also present

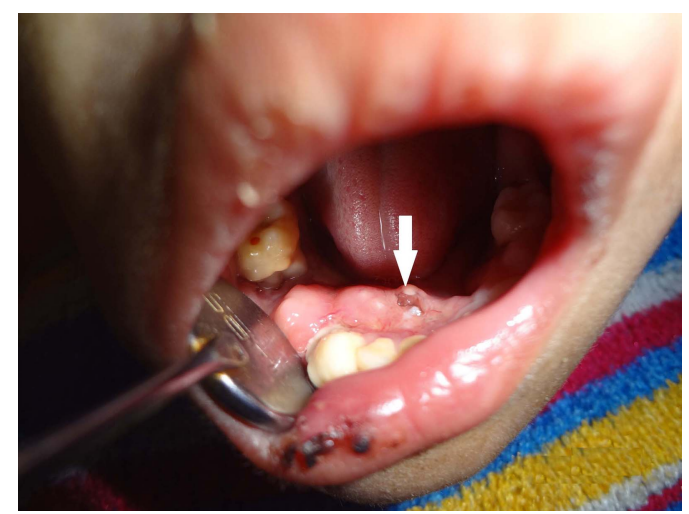

Figure 2 Intraoral photograph showing growth around the lower gingiva of the right side, with a focus of ulceration (arrow). 


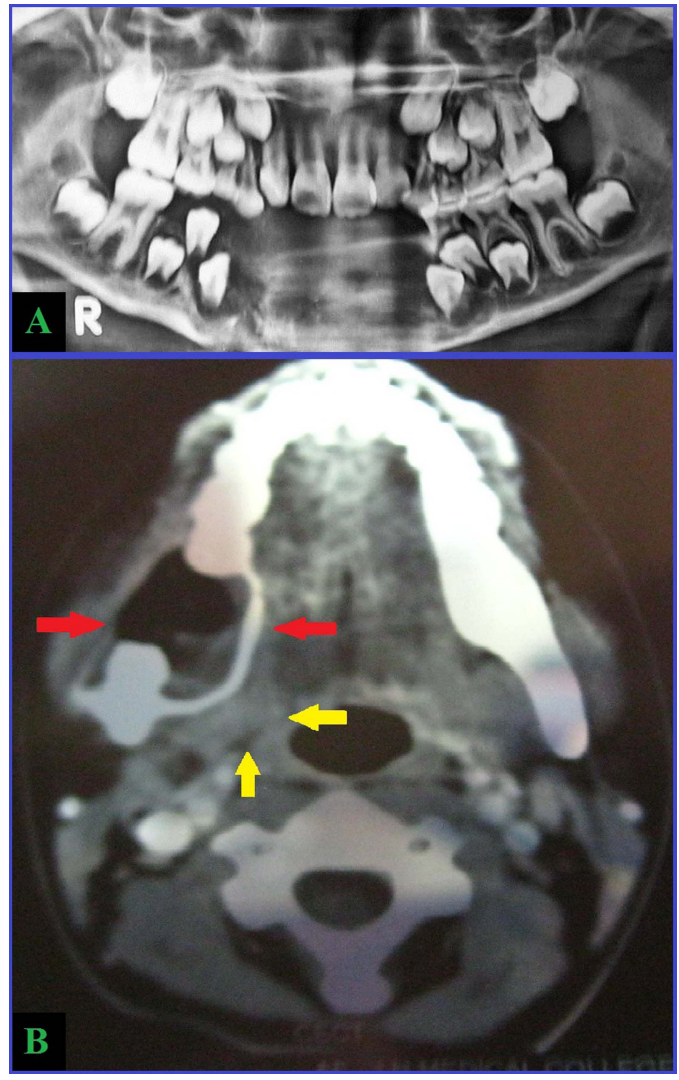

Figure 3 (A) Orthopantomogram showing radiolucency in the mandible with disruption of the teeth setting. (B) CT scan showing a lytic lesion in the alveolar part of the mandible on the right side (red arrows), with intraoral soft tissue extension (yellow arrows).

around the lesion. No regional lymphadenopathy or hepatosplenomegaly was observed.

\section{INVESTIGATIONS}

On routine workup, the haemogram was within normal limits except for raised erythrocyte sedimentation rate $(32 \mathrm{~mm} / \mathrm{h})$. Intraoral periapical radiographs and orthopantomograms showed a radiolucent area in the mandible producing the appearance of teeth 'floating in air'. CT scan, done subsequently, revealed a lytic lesion extending into the alveolar part of the mandible with intraoral soft tissue extension (figure 3). The patient was admitted for further evaluation.

Fine needle aspiration cytology of the lesion remained inconclusive as it showed only mixed inflammatory cells and macrophages. Hence an excisional biopsy was performed and the soft tissue, bony chips and teeth were sent for histopathological evaluation. On gross examination, small fragments of greyish-

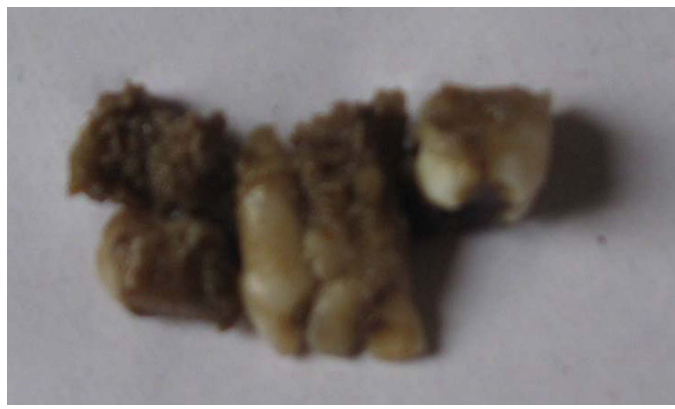

Figure 4 Gross photograph: greyish-brown soft tissue fragments with teeth and bony chips.

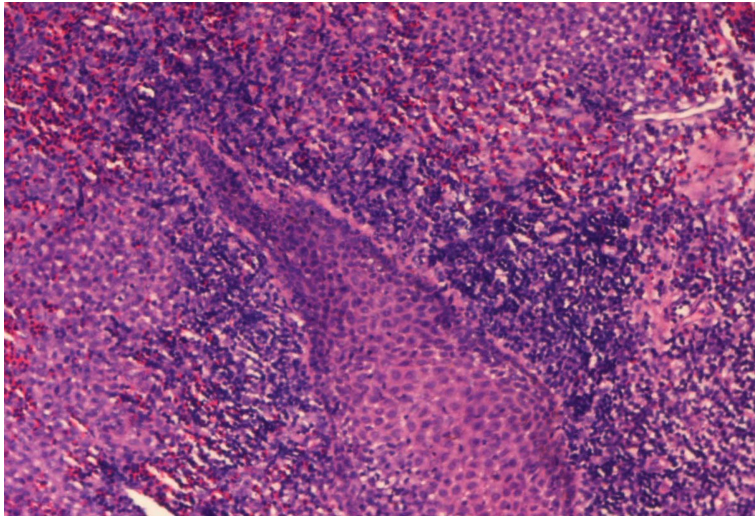

Figure 5 Microphotograph showing a dense inflammatory infiltrate underlying the stratified squamous epithelium of the gingiva and extending deep down into the submucosa. Numerous eosinophils can be identified even at this magnification (haematoxylin-eosin, $\times 40$ ).

brown soft tissue along with bony chips and teeth were observed (figure 4). Microscopic examination revealed ulceration of the mucosa accompanied by extensive aggregates of histiocytes showing a reniform nucleus, nuclear grooves and eosinophilic cytoplasm, extending deep into the underlying submucosal tissue (figure 5). Numerous eosinophils were seen lying in clusters as well as individually dispersed. In addition to these, some lymphoid cells, plasma cells and neutrophils were also present (figure 6). No malignant cells, necrosis or granulomas were seen in the sections. Thus a final diagnosis of EG was given.

\section{DIFFERENTIAL DIAGNOSIS}

In the context of the present case, osteomyelitis, EG, non-Hodgkin's lymphoma and Ewing's sarcoma were considered as clinical differentials. A rare possibility of squamous cell carcinoma of the alveolus was also considered, taking into account the non-healing ulceroproliferative gingival lesion.

The presence of fever, the age of the patient and the gingival ulceration accompanied by bone destruction on radiography favoured osteomyelitis, but the lack of response to antimicrobials and absence of bone necrosis, polymorph infiltration and granulomas on histology ruled out this possibility. Lymphoma was considered due to the presence of fever, pain over the

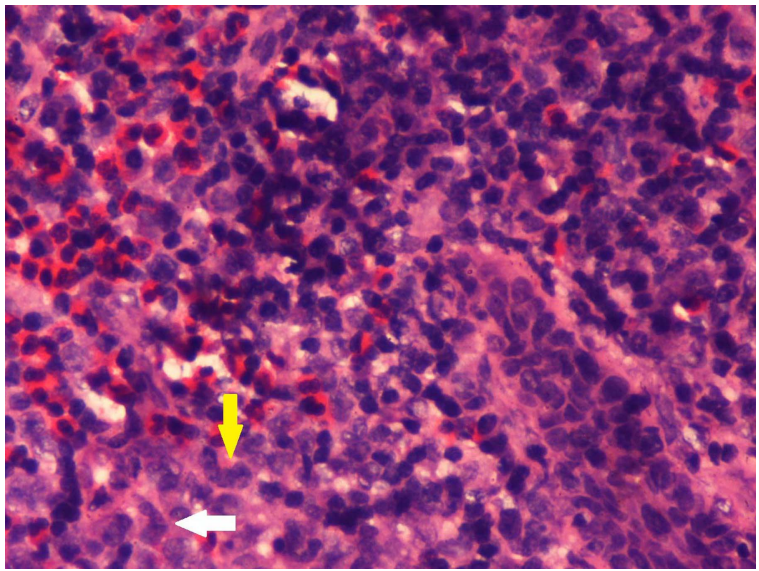

Figure 6 Microphotograph showing an abundant collection of eosinophils and lymphocytes, and characteristic macrophages with elongated nuclei and ample cytoplasm. Nuclear folding (white arrow) and reniform shape (yellow arrow) are observed (haematoxylin-eosin, $\times 400$ ). 
lesion and radiological evidence of bone destruction with sclerotic margins. However, the microscopic picture did not support a diagnosis of primary bone lymphoma. Also, the absence of a history of weight loss, lymphadenopathy and hepatosplenomegaly in the patient also did not support the probability of secondary involvement of the mandible by a lymphoma. The distant possibility of squamous cell carcinoma of the alveolus arose on the basis of the non-healing proliferative gingival ulcer accompanying the tumour, but the age of the patient, radiological picture and histopathological findings did not support this diagnosis. The characteristic microscopic picture from the biopsy also eliminated Ewing's sarcoma and hence the final diagnosis was narrowed down to EG of the mandible.

\section{TREATMENT}

The patient underwent excision of the lesion followed by bone grafting.

\section{OUTCOME AND FOLLOW-UP}

The postoperative period remained uneventful and subsequently the patient was followed-up regularly. $\mathrm{He}$ is doing well 8 months after surgery, showing no signs of recurrence.

\section{DISCUSSION}

The term 'EG of bone' was first suggested by Lichtenstein and Jeffe. ${ }^{3}$ This is a disease of unknown aetiology that arises from clonal proliferation of Langerhans cells. These cells are derived from the mononuclear cell and dendritic line precursors, and are normally found in bone marrow. Langerhans cells are specialised in their ability to migrate into tissues and act as antigen presenting cells to $\mathrm{T}$ lymphocytes. Thus they represent a 'firstline' of sensitisation of the immune system. These cells are identifiable under the electron microscope by the presence of racket-shaped cytoplasmic inclusions, known as Birbeck granules. ${ }^{4}$ It is not known, however, what leads to proliferation of these cells in LCH lesions. A variety of aetiological factors have been proposed, including immunological reactions, viruses, bacteria and genetic influences, but definitive evidence is still lacking. Some studies have suggested that the aetiology may be related to immunological abnormalities resulting from a suppressor cell deficiency. ${ }^{3} 4$

EG of bone is a rare disease. According to Gnanasekhar et al, ${ }^{5}$ the approximate incidence is one new case per 350000 to 2 million population per year. Although a wide age distribution has been reported in the literature, ranging from the neonatal period to the eighth decade, it occurs most often in young adults and children; as many as $60 \%$ of patients with solitary lesions are younger than 10 years. There is a certain predilection for males (male:female $=2: 1) .{ }^{15}$

EG of bone can occur as monostotic as well as polyostotic lesions, the former being more common. Bones of the axial skeleton, viz calvaria (especially parietal bone), jaw bone, vertebral spine and the pelvis are usually affected. In adults, the femur and ribs are the most frequent sites of the disease. ${ }^{1}$ Lesions in the long bones are most often located in the diaphysis (58\%); the epiphysis is a rare site $(2 \%) .{ }^{6}$ Miyamoto $e t a l^{7}$ observed that of all the cases of osseous EG, $7.9 \%$ involved the jaws, with angle and body of the mandible being the most commonly affected sites. In the head and neck region, EG is frequently found to affect soft tissues adjacent to the involved bones. ${ }^{467}$

Clinically, EG may not present with any physical signs or symptoms, and often it is discovered incidentally during radiographic examination for other indications. Symptomatic patients complain of gradually increasing localised swelling, pain or tenderness. As patients with EG may have low grade fever, an elevated erythrocyte sedimentation rate and mild leukocytosis, confusion with focal infective lesions is not uncommon. ${ }^{6}{ }^{8}$ In EG of jaws, destruction of the alveolar bone is thought to be one of the characteristic signs, and in this location the disease may simulate severe localised periodontitis or periapical infection. These led to malocclusion of teeth and recurrent purulent discharge from the lesions, although the pus is sterile almost all of the time. ${ }^{69}$

On plain radiographs, EG typically presents as a punched out lesion with reactive sclerosis of margins. Unifocal EG of bone has a destructive nature and the lesions tend to be well demarcated, and roughly round or oval in shape. Pathological fractures are often detectable as a testimony to the aggressive lytic nature of this neoplasm. The area of destroyed bone is replaced by a soft tissue (reddish-brown in colour), and over time the lesions become fibrous and grayish. ${ }^{9}$

The clinical and radiographic features of EG in jaws are not specific and can easily be misdiagnosed as they mimic several diseases, including osteomyelitis, odontogenic cysts, bone cysts, primary bone tumours and lymphoma. Secondly, in cases associated with marked periodontitis, the clinician's attention gets diverted more towards an inflammatory soft tissue pathology rather than EG. ${ }^{10-12}$ In such situations, histopathological examination of the lesion and its correlation with other findings is of paramount importance. The classic features of EG on histopathology are the presence of characteristic histiocytes with an oval elongated nucleus with longitudinal grooves and folds (Langerhans cells). An associated inflammatory cell population of eosinophils, plasma cells and lymphocytes are present. Areas of necrosis and giant cell reaction may be seen. The Langerhans cells show immunohistochemical positivity for S-100, CD1a and CD207 (Langerin), and negativity for CD45 (a feature that specifies the diagnosis). 136

In general, localised osseous EG needs no treatment. Spontaneous regression occurs in many patients. Symptomatic or recurrent cases may require steroid injection, curettage, excision, chemotherapy or radiation, depending on the extent of the disease and the symptoms. The prognosis is good for localised disease and malignant transformation has not been observed. ${ }^{1} 13$ In rare instances, solitary disease may recur rapidly and result in death. ${ }^{14}$ Plasschaert et al ${ }^{15}$ found that adults with EG have a higher chance of recurrence compared with children. Nevertheless, as the course of the disease can be unpredictable at times, the potential for unifocal disease to become multifocal should not be underestimated and therefore long term follow-up is mandatory. ${ }^{16}$ Monoclonal antibodies directed against CD1a or CD207 may evolve as one of the potential treatment modalities in the future. ${ }^{17}$

\section{Learning points}

- Eosinophilic granuloma of bone is a rare disease that has a predilection to involve the axial skeleton in children.

- In the head and neck region, bony lesions are frequently associated with adjacent soft tissue involvement.

- The clinical and radiographic features of eosinophilic granuloma in the jaw are not specific and tend to simulate a host of inflammatory as well as neoplastic conditions, resulting in a diagnostic dilemma.

- A high index of suspicion combined with histopathological examination is of the utmost importance in the correct diagnosis of this condition. 
Contributors RKS and KA jointly diagnosed the case on histopathology and participated in editing of the manuscript. SQ and PSR collected the clinical data, performed the literature search and prepared the manuscript.

\section{Competing interests None.}

Patient consent Obtained.

Provenance and peer review Not commissioned; externally peer reviewed.

\section{REFERENCES}

1 De Young BR, Unni KK. Langerhans cell histiocytosis. In: Fletcher CDM, Unni KK, Mertens F, eds. World Health Organization classification of tumours. Pathology and genetics of soft tissue and bone. Lyon: IARC Press, 2002:345-6.

2 Lichtenstein L. Histiocytosis $X$; integration of eosinophilic granuloma of bone, Letterer-Siwe disease and Schuller-Christian disease as related manifestations of a single nosologic entity. AMA Arch Pathol 1953;56:84-102.

3 Lichtenstein L, Jeffe HL. Eosinophilic granuloma of bone: with report of a case. Am J Pathol 1940;16:595-604.

4 Lombardi T, Hauser C, Budtz-Jörgensen E. Langerhans cells: structure, function and role in oral pathological conditions. J Oral Pathol Med 1993;22:193-202.

5 Gnanasekhar JD, Ahmed MS, Reddy RR. Multifocal Langerhans cell histiocytosis of the jaws: a case report. Quintessence Int 1991;22:559-64.

6 dos Anjos Pontual ML, da Silveira MM, de Assis Silva Lima F, et al. Eosinophilic granuloma in the jaws. Oral Surg Oral Med Oral Pathol Oral Radiol Endod 2007;104:e47-51.

7 Miyamoto H, Dance G, Wilson DF, et al. Eosinophilic granuloma of the mandibular condyle. J Oral Maxillofac Surg 2000:58:560-2.
8 Huysse WCJ, Hogendoorn RC, Bloem JL, et al. Eosinophilic granuloma of the skull. JBR-BTR 2006;89:134-5.

9 Li Z, Li ZB, Zhang W, et al. Eosinophilic granuloma of the jaws: An analysis of clinical and radiographic presentation. Oral Oncol 2006:42:574-80

10 Hartman KS. Histiocytosis X: a review of 114 cases with oral involvement. Oral Surg Oral Med Oral Pathol 1980;49:38-54.

11 Nicopoulou-Karayianni K, Mombelli A, Lang NP. Diagnostic problems of periodontitis-like lesions caused by eosinophilic granuloma. J Clin Periodontol 1989:16:505-9.

12 Shaw L, Glenwright HD. Histiocytosis X: an oral diagnostic problem. J Clin Periodontol 1988;15:312-15.

13 Watzke IM, Millesi W, Kermer C, et al. Multifocal eosinophilic granuloma of the jaw: long-term follow-up of a novel intraosseous corticoid treatment for recalcitrant lesions. Oral Surg Oral Med Oral Pathol Oral Radiol Endod 2000;90:317-22

14 Ramani P, Chandrasekar T, Baig MF, et al. Langerhans cell histiocytosis of the mandible in a six-year-old child. Indian J Dermatol Venereol Leprol 2007:73:114-16.

15 Plasschaert $F$, Craig C, Bell R, et al. Eosinophilic granuloma. A different behavior in children than in adults. J Bone Joint Surg Br 2002;84:870-2.

16 Dewan M, Al-Ghamdi AA, Zahrani MB. Lessons to be learned-Langerhans' cell histiocytosis. J R Soc Promot Health 2008:128:41-6.

17 Hicks J, Flaitz CM. Langerhans cell histiocytosis: current insights in a molecular age with emphasis on clinical oral and maxillofacial pathology practice. Oral Surg Oral Med Oral Pathol Oral Radiol Endod 2005;100(2 Suppl): S42-66.

Copyright 2014 BMJ Publishing Group. All rights reserved. For permission to reuse any of this content visit http://group.bmj.com/group/rights-licensing/permissions.

BMJ Case Report Fellows may re-use this article for personal use and teaching without any further permission.

Become a Fellow of BMJ Case Reports today and you can:

- Submit as many cases as you like

- Enjoy fast sympathetic peer review and rapid publication of accepted articles

- Access all the published articles

- Re-use any of the published material for personal use and teaching without further permission

For information on Institutional Fellowships contact consortiasales@bmjgroup.com

Visit casereports.bmj.com for more articles like this and to become a Fellow 